\title{
The Challenge to Nursing
}

\author{
SURGEON GENERAL WILLAM H. STEWART
}

W E ARE LIVING in a time in which the miraculous is taken for granted. Nine very short years ago no manmade object, however small, had ever been propelled into orbit around the world. Yet last week, when two men joined their craft to a huge orbiting gas tank 160 miles above the earth, having caught up with it in an hour and a half from a standing start, most of us were going about our business as usual. I expect it will take the first manned flight to the moon to bring us back to the level of wonder. And by the time that has been done twice, we will be ready to settle back and wait for the trip to Mars.

This casual acceptance of miracles is not confined to the space sciences. We in the health field experience our share of it. You are as aware as I am that the reach of medical potential has been extended almost beyond the imagination of physicians who practiced a generation ago.

As with the conquest of space, this revolution has been generated by brilliant advances in scientific research and brought to fruition through equally brilliant advances in applied science and technology. Also as with space, people in general have become accustomed to the medical spectacular. I suppose a genuine cancer cure would be our medical equivalent of the trip to the moon in terms of reawakened public excitement.

Dr. Stewart, Surgeon General of the Public Health Service, delivered the address on which this paper is based at a meeting of the Health and Welfare Council of Memphis, Tenn., Sept. 19, 1966.
But there is one critical flaw in this loose analogy between space and medicine. Relatively few people either want or expect to go into orbit. Everybody expects to receive the benefits of modern health science. This expectation generates tremendous pressure on the health team-the physicians, dentists, and nurses, and their allies who have to deliver the goods.

\section{Opportunity for Service}

Medicine and its allied disciplines are involved today in two simultaneous revolutions. The scientific revolution has brought an enormous enrichment of medical capability; we can do more things, better, for more people than ever before. The accompanying social and coltural revolution has caused us to raise our aspirations: instead of delivering the best in medical care to some of the people, some of the time, we are now expected to do it for all the people, all of the time.

The result of these two powerful forces is what some people are calling the "crisis in American medicine." I prefer to look upon it as an opportunity - the greatest opportunity for service that has ever been presented to a generation of health workers.

If we are to meet this challenge, we need to take a cold, hard look at our resources. Where they are inadequate for the job that society expects us to do, we need to plan and undertake realistic actions that will make them strong enough. If such actions require adjustments on our part, we need to adjust. If they require adjustments on the part of society, we need to say so forcefully and repeatedly. 
Let us assess the most fundamental resource of all-health manpower. I am going to concentrate attention primarily on a single profession-nursing. I shall do so partly because the health manpower field is extremely wide and I must be brief. Chiefly, however, I am concentrating on nursing because no single group is more important to the day-by-day delivery of health care than nurses, and because none of the health professions is at a more critical moment in its development.

In common with the other health professions, nursing is being severely challenged by the two revolutions. The scientific revolution has forced an acceleration of specialization among physicians as the tasks they perform become increasingly complex. This process in turn has forced specialization on nurses, requiring them to take on new and complex responsibilities.

For example, intensive care units for coronary patients are proving highly successful in saving lives during hospitalization. These units are based upon continuous monitoring--usually by electronic means-of pulse, respiration, and other critical indicators. A highly trained nurse is quite literally at the controls. When her panel indicates a moment of emergency, she is at the barricade between life and death. Her oall to the physician, and her action until he arrives, decide the issue.

Plainly, this is a far cry from the tea-andsympathy image of nursing. It calls for high capability and highly specialized training. Thus the first impact on nursing of the scientific revolution has been an insistence on quality.

\section{The Nursing Shortage}

Meanwhile the social forces that have combined to increase the demand for health care have created an overwhelming need for quantity of nursing service. The words "nursing" and "shortage" have been used together so universally and for so long that they seem almost to have merged in general conversation. However, until recent months, the condition seemed to be one of those chronic ailments which cause constant discomfort but produce only an occasional flareup of real pain.

But early this year there appeared to be a marked turn for the worse in the condition of nursing all over the nation. The problem that had been filed in the back of the public mind began to command immediate and urgent attention.

At midyear, the Public Health Service announced that the shortage of nurses nationwide was 125,000 . But this figure is more meaningful if we look at specific problems around the country.

One hospital in New York was forced to delay opening many of its facilities because of a shortage of nurses, and it was announced that 60 percent of the registered nurse positions in municipal hospitals in New York City are vacant. The Colorado Nurses' Association said that the shortage of nurses in the Denver metropolitan area is conservatively estimated at nearly 300. A unit of a hospital in Philadelphia was closed temporarily because it could not find nurses during the summer vacation period. The Georgia Hospital Association, on the basis of a statewide survey, estimated that an additional 400 nurses could be employed in Atlanta alone. A hospital in Florida planned to increase facilities for patient care in that area by erecting a new hospital building and continuing to use the older structure; however, after a period of almost desperate recruitment, officials issued a press release stating that the shortage of nurses had forced them to close the older buildings.

The nurse shortage plaguing Massachusetts flared into an emergency situation, and the State issued an appeal to all inactive nurses to return to work immediately. In a letter to every nurse registered or licensed in Massachusetts, the director of the division of employment security said: "If you are not now working as a nurse in Massachusetts and can answer this emergency call, go to the Massachusetts State Employment Office nearest you and ask about a nursing position in your community or for a refresher course."

\section{The Troubled Profession}

The situation in Massachusetts underscores an ironic aspect of the nursing problem. There are more than a million registered professional nurses in the United States. But only a little more than half of the nurses are in active practice, and about a fourth of these are working part-time. We are, therefore, confronted with 
a profession which is actually functioning at less than half of its potential. This fact alone should warn us that all is not right in nursing.

About the same time that shortages began to hit the headlines, the latent discontent among nurses over salaries and working conditions unexpectedly erupted into mass resignations and bargaining sessions from New York to California. The Wall Street Journal wryly commented, "Florence Nightingale all of a sudden is sounding like Samuel Gompers." But it is important to note that their sympathy was with the Florence Nightingales. The Washington, D.C., Star termed nurses the "forgotten profession," and editorialized, "The facts are all on the side of the nurses. They deserve better, and they must get it-soon." The editorial pointed to a U.S. Bureau of Labor Statistics report revealing that in 1963-64 salaries of classroom teachers averaged $\$ 6,235$ a year, secretaries $\$ 5,170$, and factory workers $\$ 5,075$. In the same period, salaries of general duty nurses in non-Federal city hospitals - the largest group of nurses-averaged $\$ 4,500$. "This is a problem that feeds on its own shortcomings," the editorial said. "The lower the pay, the more women resign and the fewer students are encouraged to enter the profession. This in turn throws an ever greater burden on those who remain."

If we are amazed or shocked because nurses are protesting throughout the country, it is because we have indeed been taking them for granted. The time is here when we have no choice but to listen. Nurses in an Illinois city declare that the dogcatcher makes more money than they do. The nurses in a California hospital have pointed out that their salaries range from $\$ 425$ to $\$ 485$ a month, while the gardener at the hospital earns $\$ 572$ a month.

Salaries are the most obvious, most easily demonstrated cause of unrest in the nursing profession. But pay is by no means the only problem. Unsatisfactory working conditions are cited as frequently as low salaries when nurses are asked why they are leaving the profession.

The major complaint seems to be a sense of frustration because nurses feel that they are not able to do what they entered nursing to do-take care of patients. They point out that professional nurses are deluged by paperwork and supervision and training of the many layers of assistants-practical nurses, aides, and orderlies-who function between themselves and the patients. In addition, because nursing services operate 24 hours a day, 365 days a year, professional nurses are frequently called upon to absorb the responsibilities of other health workers who work on conventional hours. At various times nurses substitute for physicians, anesthetists, hospital administrators, dietitians, laboratory technicians, and scrubwomen. They worry about the quality of care patients receive in such conditions of stress. They also worry about the adequacy of their own training and of the training of those who perform nursing tasks while they are doing something else.

Moreover, there are serious problems of career development. Graduates of hospital schools of nursing - about 85 percent of our national nursing resource-quickly find that they cannot advance beyond a certain level without an academic degree. When they seek the degree, they generally find that their 3 years of hospital training does not merit a single academic credit. They have to start all over. Most of them, understandably, do not.

\section{Finding a Solution}

Thus, nursing is a deeply troubled profession, beset by multiple problems which are much easier to describe and document than to solve.

Consider, for example, the matter of salaries. Although nurses serve many types of institutions, those who work in hospitals comprise the largest single group. The hospital situation has, therefore, received the greatest attention. Often the hospital has been portrayed as the villain of the piece, but it is not that simple. Hospital administrators face upward-spiraling costs-many stemming from advances in medical science that require costly equipment and procedures. Nursing salaries and services represent a major portion of the hospital budget. It is not easy to work an overnight miracle to raise nursing salaries to the levels where they belong.

Yet I am convinced that it must be done, and done quickly. If corner must be cut, we must look for other corners. Most hospitals are decades behind in business management practices. 
Moreover new sources of funds are becoming available. Medicare, for example, will pay in full for the care of many patients whose bills were formerly absorbed in part by the hospitals.

With regard to the less tangible but no less important problems of professional stature and conditions of employment, the entire health enterprise has an enormous job to do. Hospital administrators, physicians, officials of governmental agencies at all levels, and nurses themselves need to ask soul-searching questions about the adjustment to scientific medicine which is still in process.

Who should be trained to perform which functions? By whom should they be trained? Should we go on spawning new specialties, subspecialties and supportive subdisciplines? Should the future of nursing be hitched to the star of science? If so, to what extent is this compatible with the traditional patterns of bedside care? Does the present four-track system of nursing education-practical nurse school, junior college, hospital-school, and baccalaureate degree-make sense in terms of future needs? If not, how can it be improved and what can be done in the meantime to provide for sensible interlocks and logical career progressions? What relatively simple things can we do to enable women to be wives and mothers and also practicing nurses?

All these questions, and many more, require thoughtful consideration, experimentation, innovation. We cannot light modern medicine with Clara Barton's lamp, any more than we can time it by the traditional country doctor's pocket-watch.

A few years ago the nation stood in grave danger of losing quality in teaching. Then came sputnik, and suddenly we realized that we needed very badly to do something very quickly for the teaching profession. Whether or not it was for the right reason, a great many right things took place. Private foundations, universities, local and State school boards, and the Federal Government moved swiftly and decisively to act upon a powerful surge of public insistence on better education. The money was not there and the ideas were not there when we started, but we found them when we wanted them enough.

We have not yet had our medical sputnik. It is difficult to imagine an externally imposed motivation that would trigger a similar response.

But we do have a strong tide of public expectation for the best in health care. I do not think we need a sputnik. I think that this public expectation can give us all the impetus we need. It makes the "health crisis" the greatest opportunity we have ever had.

To meet this challenge we need to answer the hard questions. We need to present those answers to the people who look to us for health service. I am confident that they will respond with the support required to fulfill their expectations.

No single element of the health partnership can answer the questions alone-not the individual professions, nor academic medicine, nor the hospitals, nor government. Groups like your health and welfare planning councils furnish excellent meeting grounds for hammering out workable solutions, responsive to the needs of the health professions and the people they serve. If we work together across artificial boundary lines that separate profession from profession and sector from sector, I know we can do the job. 